\title{
METROPOLIS - A DISTOPIA URBANA DO CINEMA EXPRESSIONISTA ALEMÃO E SUA INFLUÊNCIA NOS FILMES DE FICÇÃO CIENTÍFICA
}

\author{
Metropolis - the urban dystopia of german expressionist cinema and its \\ influence in science fiction films
}

Metropolis - distopía urbano de cine expresionista alemán y su influencia en las películas de ficción científica

\author{
José D'Assunção Barros \\ Universidade Federal Rural do Rio de Janeiro (UFRRJ) \\ jose.d.assun@globomail.com
}

\begin{abstract}
Resumo
Este artigo examina, no quadro das cidades imaginárias produzidas pelas distopias futuristas encaminhadas pelo Cinema, a cidade futurista Metropolis, elaborada pelo filme de mesmo nome na primeira metade do século XX. Examina-se elementos de sua arquitetura, espacialidade, organização social, e buscando perceber a sua articulação com o roteiro do filme. A hipótese de trabalho apresentada é a de que as cidades imaginárias sempre expressam, de alguma forma, os medos, angústias, anseios, esperanças ou demandas da sociedade que as produziu. Neste sentido, operacionaliza-se aqui a postura metodológica que considera o real e o imaginário não como dimensões separáveis, mas complementares e constituintes de uma unidade complexa.
\end{abstract}

Palavras-Chave: Cinema. Cidade. Futuro. Imaginário. Distopia.

\begin{abstract}
In this article, we are going to examine, in the ambit of the imaginary cities produced by the distopic cities of the Cinema, the futuristic city of Metropolis. It will be examined examine elements from its architecture, spatiality, social organization, and also searching to perceive its articulation with the film plan. The hypothesis is that the imaginary cities always show the fears, desires, hopes and demands of the society witch have produced the film. In this way, we apply here the methodological posture that considers the Real and the Imaginary not as separated dimensions, but complementary and inserted in a complex unity.
\end{abstract}

Key-Words: Cinema. City. Future. Imaginary. Dystopia. 


\section{Resumen}

Este artículo examina en el contexto de las ciudades imaginarias producidas por distopías futuristas remitidos por el cine la ciudad futurista Metropolis, establecido por la película del mismo nombre en la primera mitad del siglo XX. Examina los elementos de su arquitectura, la espacialidad, la organización social, tratando de darse cuenta de su conexión con el guión. La hipótesis de trabajo que se presenta es que las ciudades imaginarias expresan siempre, de alguna manera, miedos, ansiedades, deseos, esperanzas y demandas de la sociedad que los produjo. En este sentido, se operacionaliza aquí el enfoque metodológico que considera lo real y lo imaginario no como dimensiones separables, pero complementarias y componentes de una unidad compleja.

Palabras clave: Cine. Ciudad. Futuro. Imaginario. Distopía.

\section{INTRODUÇÃO}

As cidades imaginárias sempre expressam, de alguma forma, os medos, angústias, anseios, esperanças ou demandas da sociedade que as produziram. Neste artigo, examinaremos uma distopia urbana criada pelo cinema expressionista na primeira metade do século XX - a Metrópolis, de Fritz Lang - e operacionalizaremos aqui a postura metodológica que considera o real e o imaginário não como dimensões separáveis, mas sim percebendo a sua "unidade complexa e a sua complementaridade"1.

"Metrópolis", uma gigantesca metrópole futurista imaginada pelo Cinema da primeira metade do século XX, foi idealizada em 1926 pelo cineasta alemão Fritz Lang no filme de mesmo nome ${ }^{2}$. Fritz Lang (1890-1976) estava associado a uma corrente estética específica do Cinema Alemão - o Cinema Expressionista - e, conforme veremos, uma das mais fortes tônicas desta corrente era precisamente a crítica social, alinhada a certa visão pessimista que, no período abarcado pelas Guerras Mundiais e pelo entre-guerras, buscava expressar de maneira particularmente intensa os temores, angústias e insatisfações do homem

\footnotetext{
${ }^{1}$ MORIN, Edgar. O Cinema ou o Homem Imaginário. Lisboa: Relógio D’Água, 1997 [original: 1956]

${ }^{2} \mathrm{O}$ filme Metrópolis foi uma das primeiras superproduções da História do Cinema. Seu orçamento foi bastante elevado para a época (5 milhões de marcos) e suas filmagens duraram praticamente um ano, contando com cerca de 36000 extras envolvidos nos trabalhos de filmagem (25000 homens, 11000 mulheres e 250 crianças). O fracasso de bilheteria, contudo, colocou os seus financiadores em estado de falência, embora anos mais tarde o filme tenha passado a ser considerado uma obra-prima. Em 1984, Giorgio Moroder (n.1940) produziu uma versão a cores, e reduzida das 3 horas originais para 1 hora e 20 minutos, acrescentando uma trilha sonora com música do Queen. Em 1995 seria produzida nova versão em preto e branco do filme, com 2 horas e 33 minutos. A película original de Metrópolis, que se extraviara, foi reencontrada mais recentemente na Argentina, revelando cenas até então desconhecidas.
}

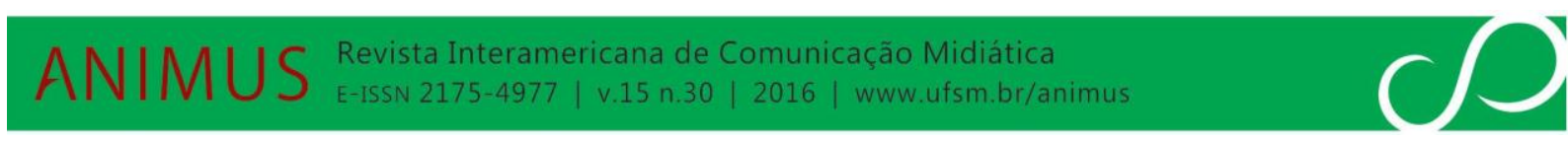


urbano $^{3}$. Estas características - que de resto foram recorrentes no Expressionismo também relacionado a outras formas de manifestação artísticas como a Pintura, a Música e a Poesia vêem-se acrescidas na linguagem fílmica de certas tendências técnicas e estéticas, como "a expressividade dos cenários, o tratamento mágico da luz e a morbidez dos temas"4. No contexto expressionista de crítica social, e de acordo com esta linguagem fílmica, Metrópolis buscaria construir um retrato distópico das cidades do futuro - entendendo por "distopia” uma utopia negativa ${ }^{5}$.

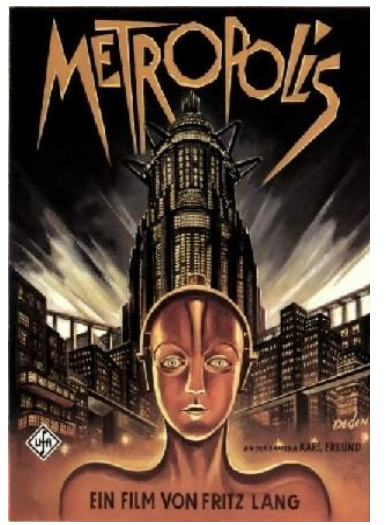

Figura 1: Cartaz de divulgação de Metrópolis, de Fritz Lang.

Imagem disponível em http://ning.it/hvpQgb

\begin{abstract}
${ }^{3}$ O grande marco do Cinema Expressionista é o filme $O$ Gabinete do Dr. Caligari, dirigido em 1920 por Robert Wiene (1873-1938). Para uma visão geral do expressionismo alemão, ver CÁNEPA, Laura Loguércio, "Expressionismo Alemão" in MASCARELlO, Fernando (org.), História do Cinema Mundial, São Paulo: Papirus, 2006. Para uma compreensão do Expressionismo como movimento artístico mais amplo, ver CARDINAL, R., O Expressionismo, Rio de Janeiro: Jorge Zahar, 1988. Para uma avaliação estética e histórica das diversas correntes do Cinema Alemão nas primeiras décadas do século XX, ver KRACAUER, Siegfried, De Caligari a Hitler: uma história psicológica do Cinema Alemão, Rio de Janeiro: Jorge Zahar, 1988. Para o contexto artístico-cultural do Cinema Alemão da época da República de Weimar, ver ELSAESSER, T. (org), Weimar cinema and after: Germany's historical imaginary. Londres: Routledge, 2000. Sobre o contexto histórico mais amplo da República de Weimar, ver (1) GAY, Peter, A cultura de Weimar, Rio de Janeiro: Paz e Terra, 1978, e também (2) JONES, L. E. "Culture and politics in the Weimar Republic" in MARTEL, G (org) Modern Germany reconsidered (1870-1945), Londres: Routledge, 1992.

${ }^{4}$ CÁNEPA, Laura Laguércio, "Expresionismo Alemão”, op.cit., p.69.

5 Sobre o uso do conceito de "distopia" como "utopia negativa" ver JACOBY, Russell. Imagem Imperfeita: Pensamento Utópico para uma Época Antiutópica. Rio de Janeiro: Civilização Brasileira, 2007, p. 31. Ver também KUMAR, Krishan, Utopia and Anti-Utopia in Modern Times, Cambridge Ma: Oxford UK, 1987, p.100. Já associado a modelos imaginários positivos, o conceito de "utopia" tem em algumas realizações literárias exemplos já clássicos, como a Utopia de Thomas Morus (1478-1535), que celebrizou a expressão (MORUS, Thomas. "Utopia" in Os Pensadores. São Paulo: Abril Cultural, 1980, vol.12), a Cidade do Sol de Tomaso Campanella (Os Pensadores. São Paulo: Abril Cultural, 1980, volume 12), ou a Nova Atlântida, de Francis Bacon (publicada no vol. 13 de Os Pensadores. São Paulo: Abril Cultural, 1980). Antes destes autores renascentistas e barrocos, e mesmo no período clássico da Antiguidade Grega, Platão concebeu a sua República como um modelo de cidade imaginária positivo, de maneira que também podemos nos referir a sua idealização como uma construção utópica (PLATÃO, A República, Lisboa: Fundação Calouste Gulbenkian, 1993).
\end{abstract}

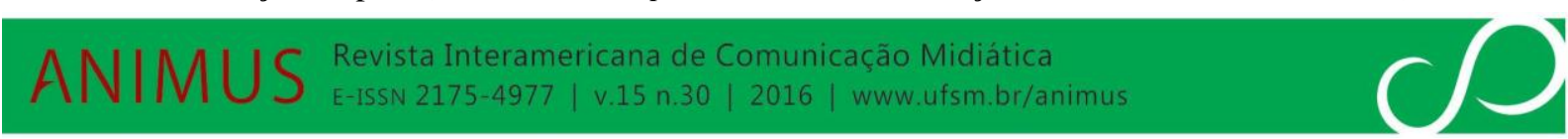


O filme Metrópolis, à parte a sua leitura específica de um dos futuros possíveis para as sociedades urbanizadas, marcou época na história do Cinema e estendeu influências consideráveis tanto no que se refere de maneira geral aos futuros filmes de ficção-científica, que seriam produzidos nas décadas subseqüentes, como no que se refere à produção de um imaginário futurista da cidade. Estamos ainda diante de um filme mudo, mas bastante impressionante no que se refere aos seus arrojados efeitos especiais e cenários futuristas. Além disto, a distopia traçada por Lang teria bastante influência sobre outras antevisões, no Cinema e na Literatura, a respeito de sociedades dominadas por regimes totalitários que poderiam reduzir grandes massas humanas a uma nova forma de escravidão regida por um rigoroso e sofisticado controle social amparado por uma eficiente tecnologia. Para entender a importância da Metrópolis de Fritz Lang na história das cidades imaginárias distópicas, basta lembrar que a célebre novela Admirável Mundo Novo, de Aldous Huxley (1894-1963), só seria escrita quatro anos mais tarde, em 1931, e levada ao cinema em $1933^{6}$. Esse modelo de totalitarismo futurista apoiado na eficiência tecnológica, na desumanização, na vigilância absoluta e na consolidação definitiva da desigualdade social encontraria sua realização mais popularizada no famoso livro de George Orwell intitulado "1984"7, mas já no filme "Metrópolis" de Fritz Lang encontraremos um modelo bastante impressionante ${ }^{8}$.

\footnotetext{
${ }^{6}$ A bem conhecida obra Admirável Mundo Novo, de Aldous Huxley (1894-1963) constitui um dos mais notáveis modelos distópicos (HUSLEY, Aldous. Admirável Mundo Novo, São Paulo: Abril Cultural, 1974). Muito antes da idealização literária de Huxley, porém, H. G. Wells (1866-1946) já havia produzido uma impressionante distopia literária com A Ilha do Doutor Moreau (1896), obra que chega ao Cinema em 1933, sob a direção de Erle C. Kenton (1896-1980) e produzida pela Paramount Pictures, em uma versão de 71 minutos. Quanto ao Admirável Mundo Novo, foi produzido em 1980 um filme para a televisão, sob a direção de Burt Brinckerhoff (n.1936), e com um elenco encimado por Tara Buckman. Sobre o papel de Wells na história do pensamento distópico, ver HILLEGAS, Mark R. The Future As Nightmare: H.G. Wells and the Anti-Utopians. Illinois: Southern Illinois University Press, 1967.

7 ORWELL, George, 1984, Lisboa: Antígona, 2004. A obra 1984 foi idealizada por Orwell (1903-1950) em 1948, e a própria escolha da data é um anagrama do ano em que foi concebido (1948 - 1984). O livro começa a ser escrito em agosto de 1946, e é concluído em novembro de 1948. Uma das principais características desta utopia orwelliana -além do controle absoluto encaminhado pela tecnologia e da estratificação social inflexível é o fato de que a sociedade descrita por Orwell apresenta um eterno presente no qual a História é reescrita todos os dias, particularmente em função das flutuações no jogo de alianças e hostilidades entre as três superpotências que dominam o mundo imaginado por Orwell. Ao Cinema, depois de uma versão anterior em preto e branco, 1984 chega às telas em um filme de Michael Bradford, rodado em Londres entre abril e junho de 1984. Uma distopia similar a 1984 também é trazida ao Cinema pelo filme Brazil, de Terry Gilliam (n.1940), que contou com um elenco encabeçado por Jonathan Price. O trailer de 1984 pode ser encontrado em http://ning.it/gU2vlD.

8 Sintomaticamente, há também uma possibilidade de leitura de Metrópolis como obra sintonizada com o Nazismo em formação e em busca de ascensão, conforme mencionaremos adiante. Na verdade, os receios com relação a futuros totalitaristas surgiram à direita e à esquerda naquele momento da história cultural européia. Fritz Lang, mais propriamente, não se interessava pela política convencional, embora sua esposa Thea von Harbou (1888-1954), co-autora do roteiro, estivesse engajada na militância do Partido Nacional-Socialista à época das filmagens de Metrópolis.
}

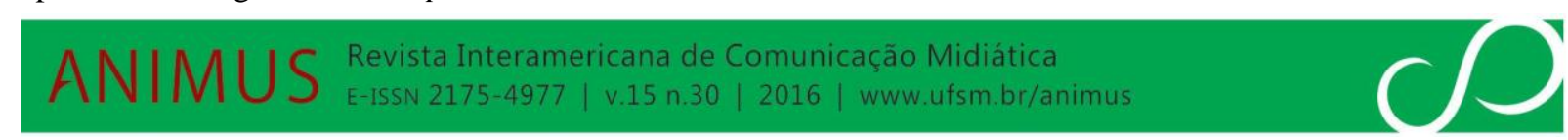


A Cidade-Cinema trazida por Metrópolis busca concretizar um modelo futurista, com base no imaginário da época a respeito de como seria o mundo dali a cem anos, e incorpora de maneira particularmente intensa certa ordem de contradições que parecem desnudar os medos de toda uma parcela da sociedade perante possibilidades que parecem se anunciar no contexto da implantação do fordismo e da urbanização desmedida. Entre estes "medos" tão típicos da primeira metade do século, podemos citar os receios diante dos usos desumanos da tecnologia, as angústias relacionadas a expectativas do desemprego que poderia ser produzido através da substituição do trabalhador humano pela máquina, a desumanização cotidiana promovida pela rotina mecanizada, e o paradoxal isolamento do homem em um mundo superpovoado, socialmente dividido e envolvido pelo artificialismo e controle tecnológico ${ }^{9}$.

Todos estes medos, de algum modo, estão à flor da pele no período de gestação do filme de Fritz Lang, e é assim que o cineasta nos revela em sua Metrópolis arranha-céus ao mesmo tempo magníficos e sombrios, fascinantes e aterradores, palcos para uma vida extremamente organizada e sofisticados berços para a solidão humana ${ }^{10}$. De igual maneira, o intenso contraste entre estes gigantescos prédios e as ruas por vezes estreitas que constituem parte do traçado da cidade - contraste que mais tarde também seria bem explorado pelos autores do filme de Blade Runner ${ }^{11}$ - traz ao espectador do filme, como primeira impressão, uma angustiante sensação de claustrofobia. Em Metrópolis, parecem estar superpostos uma arquitetura industrial hiper-moderna e uma atmosfera gótica, bem ao gosto do revival medieval que encontra acolhida em outras produções artísticas da Alemanha da mesma época. Um destaque da arquitetura simultaneamente hiper-moderna, e carregada de uma atmosfera gótica, é a Torre de Babel, uma construção arquitetônica com teto de cinco pontas que domina a paisagem urbana de Metrópolis:

\footnotetext{
9 Temas como o desemprego nas sociedades industriais, a desumanização do homem através da produção mecanizada, a alienação do trabalhador inserido na linha de montagem, ou o controle da tecnologia sobre todas as ações humanas estariam em pauta também em outros filmes do período, como em Tempos Modernos (1936), um filme em preto e branco produzido, dirigido e estrelado por Charles Chaplin (1889-1997). Temas cênicos que já aparecem em Metrópolis, como o do operário que é engolido pela Máquina ou que chega a se confundir com suas engrenagens, serão retomados pelo cineasta inglês de maneira particularmente bem humorada. Ver a famosa cena do enlouquecimento de um operário (Charles Chaplin) em http://ning.it/eAPQok.

${ }^{10}$ Fritz Lang em 1924, dois anos antes da produção de Metrópolis, teria visitado os Estados Unidos e ficado bastante impressionado com a altura desmedida dos arranha-céus de Nova York.

${ }^{11}$ Blade Runner, de Ridley Scott, constrói sua cidade futuresca tomando a Metrópolis de Fritz Lang como referência, embora lhe acrescentando uma série de aspectos que já seriam demandas de um novo tempo.
}

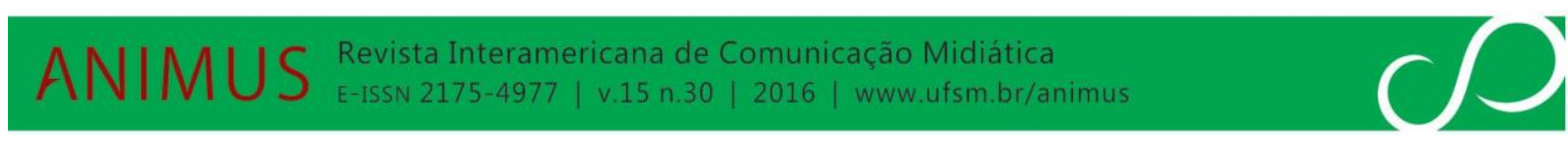




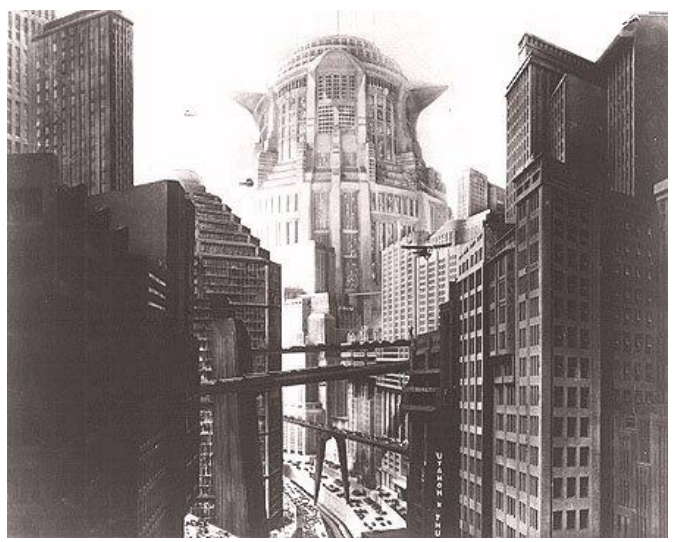

Figura 2: “Torre de Babel”, Metrópolis. Foto de cena.

Foto disponível em http://ning.it/hvpQgb

Particularmente interessante é o impacto que causa - e mais ainda deve ter causado no espectador da primeira metade do século XX - a imagem de aviões e veículos voadores transitando entre os edifícios. Um avião sobrevoando o céu, para um imaginário comum, coloca-se habitualmente como a imagem que representa a altura por excelência. Para o olhar cotidiano, fora os próprios astros que pulsam para além da Terra, nada pode se situar para além da altura do avião que sobrevoa uma cidade. O avião, particularmente nesta época em que os foguetes ainda eram sonhos tecnológicos, representa a altura máxima atingida pelo homem. Colocar aviões voando entre edifícios é uma ousadia imagética considerável, que cria um efeito que estica ainda mais a altura dos arranha-céus imaginados pelo cineasta. Este impacto visual será retomado em filmes posteriores, como é o caso de O Quinto Elemento (1997).

Mas retomemos ao ambiente espacial proposto pela Metrópolis, avançando para uma compreensão da sociedade que sob ele se abriga. Vivendo nestes arranha-céus incomensuravelmente altos e usufruindo seus momentos de lazer nos jardins situados nos terraços dos edifícios, uma parte da humanidade parece se beneficiar de todo o conforto proporcionado pela vida moderna. Desta maneira, ao lado de fantásticos e sofisticados prédios, como é o caso dos impressionantes edifícios em ziguezague de Metrópolis, há também um espaço para o lazer no terraço dos edifícios, assegurando à elite que habita Metrópolis um paliativo lúdico para este ambiente superpovoado e por vezes claustrofóbico. Esta era, enfim, a parte mais visível da Metrópolis de Fritz Lang. Mais adiante, veremos que uma segunda cidade, bem distinta, esconde-se sob esta, debaixo da terra. 


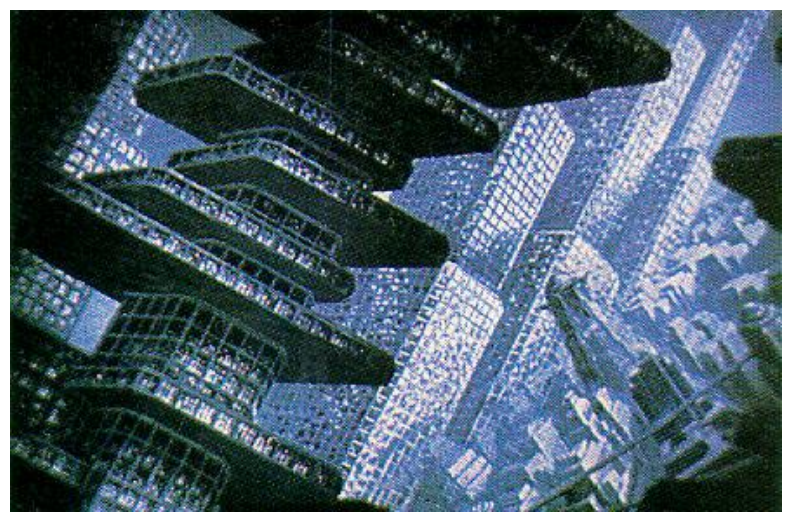

Figura 3: Edifícios em Ziguezague. Metrópolis.

Desenho de Erich Kettelhut. Berlim: Filmmuseum

Disponível em http://ning.it/hUTX5c

Todos os receios e temores de uma sociedade européia diante de um mundo que começava a se superpovoar e a acenar com possibilidades de uso desumano da tecnologia parecem encontrar seu lugar neste ambiente simultaneamente sombrio e tecnologicamente fascinante que é construído por Fritz Lang. Assim, as auto-estradas são congestionadas, os arranha-céus extrapolam em altura, a poluição atinge níveis ameaçadores, e um relógio assinala obsessivamente as horas, com uma impiedosa pontualidade que conforma toda a vida urbana. Essas dimensões constrangedoras e angustiantes da vida citadina são levemente contrastadas pelos agradáveis jardins floridos situados no alto dos arranha-céus e pelo conforto tecnológico proporcionado aos habitantes desta parte privilegiada da cidade, mas de todo modo revelam-se bem presentes na Metrópolis de Fritz Lang as inquietações do homem europeu da primeira metade do século XX diante do mundo urbano em desenfreado crescimento. O aspecto mais terrível, contudo, é a estruturação social que se revela emoldurada por esta cidade futurista, reservando para os seus subterrâneos ocultos uma terrível exploração social e uma radical perda das identidades individuais em favor da transformação de uma grande massa de trabalhadoras subalternos em formigas destinadas a alimentar a Máquina ${ }^{12}$. Assim, em contraste com o ambiente futurista acima descrito, a parte mais inferior de Metrópolis esconde uma cinzenta cidade-dormitório, de construções simples

${ }^{12}$ Esse aspecto é bem abordado por EISNER, L.H. A tela demoníaca, as influências de Max Reinhardt e do expressionismo. Rio de Janeiro: Paz e Terra Instituto Goethe, 1985. 
e rigorosamente padronizadas. Vejamos, em seguida, como este duplo ambiente urbano aparece no decorrer do enredo de Metrópolis.

O filme se passa em 2026, uma época em que - de acordo com a construção expressionista de Fritz Lang - teria como principal característica uma sociedade radicalmente dividida em duas classes distintas, o que se concretizaria inclusive em uma espacialização da própria desigualdade social a partir de um mundo dividido em dois ambientes bem diferenciados. De fato, o filme já nos mostra logo em suas cenas iniciais uma Cidade dividida em duas: uma parte inferior e subterrânea, conhecida como a "cidade dos trabalhadores", e uma parte superior, na superfície, conhecida como "Club of the Sons". De um lado estaria uma classe privilegiada, liderada por uma elite dominante, e que vive na superfície em gigantescas estruturas arquitetônicas envolvidas por um interminável fluxo de trens, carros e veículos voadores. De outro lado estariam os operários, condenados a uma vida escrava em uma espacialidade urbana situada muito abaixo do solo.

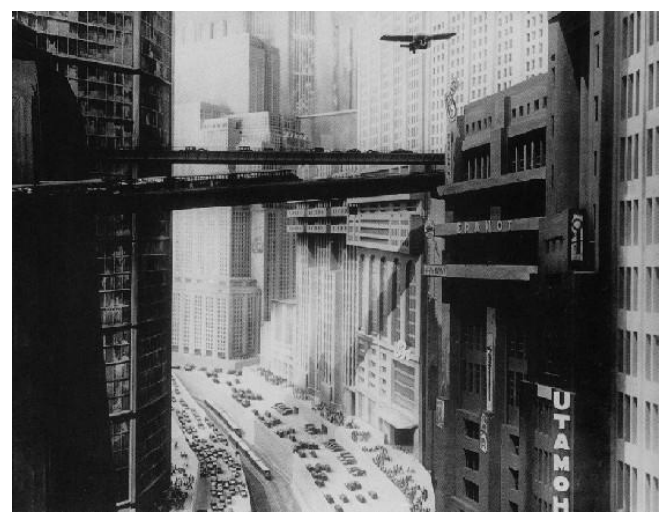

Figura 4: Metrópolis. Cena mostrando o envolvente fluxo de automóveis, trens suspensos e veículos voadores, por entre as gigantescas construções arquitetônicas. Foto disponível em http://ning.it/hvpQgb

O contraste entre as duas espacialidades, e as duas humanidades por elas forjadas, é brutal já desde a primeira cena do filme. Aparecem aqui os operários no encerramento de mais uma dura jornada de 10 horas de trabalho, todos se dirigindo para os elevadores que os conduzirão de volta às cidades subterrâneas, onde residem as suas famílias. Caminham lentamente, a passos marcados como se fossem prisioneiros de guerra, cabisbaixos e desolados, e ao som de uma trilha sonora profundamente melancólica e depressiva. A segunda cena traz a primeiro plano os habitantes da superfície: jovens praticam esportes em um ambiente lúdico, ao som de uma trilha sonora alegre e grandiosa. Este contraste será a base 
essencial do filme e vai mais além. Na verdade, a região na qual residem os operários é ainda uma região inferior, mais obscura e situada bem abaixo da terra, abaixo mesmo da Fábrica e da zona de máquinas que acolhe diariamente o seu árduo trabalho.

Entre estes dois ambientes - o da superfície habitada pela elite (os mestres) e o das profundezas nas quais residem as massas operárias - estaria precisamente a zona na qual se localizariam pesadas e complexas máquinas destinadas a manter o conforto e lazer na superfície. As máquinas, naturalmente, necessitavam do incessante trabalho dos operários. Uma das imagens mais impressionantes construídas por Lang, aliás, é aquela em que, durante a jornada de trabalho, os diversos operários se encaixam nas máquinas como se fizessem parte de suas anatomias - acomodando-se tão perfeitamente às reentrâncias de cada máquina a ser operada que, nestes momentos, já não é possível distinguir homem e máquina. Décadas mais tarde, a imagem do homem que alimenta a máquina com seu próprio corpo e com sua própria alma seria retomada pelo filme Matrix, constituindo uma nova metáfora para a alienação.

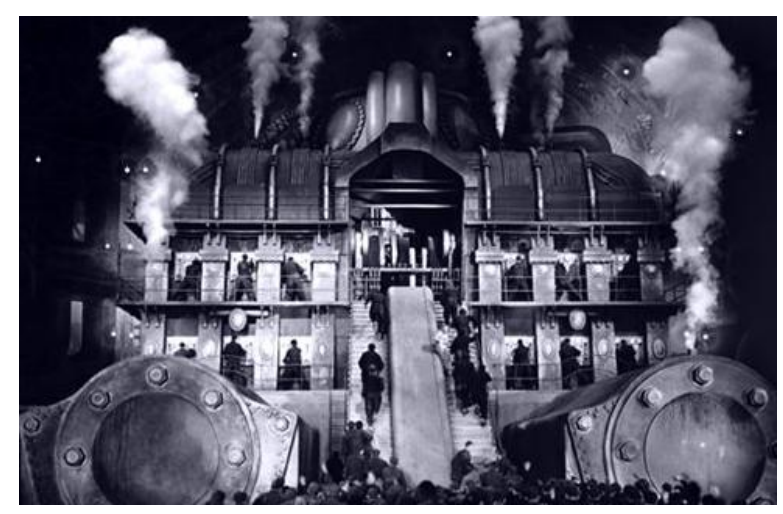

Figura 5. Casa das Máquinas. Metrópolis.

Máquina acomodando operários nos seus nichos Imagens disponíveis em http://ning.it/fYNLRn

De todo modo, na Metrópolis idealizada por Lang, as gigantescas máquinas, situadas entre o ambiente urbano da superfície e a zona habitacional dos operários, precisavam ser acionadas e operadas a partir de grandes alavancas, e controladas por intermédio de painéis cobertos de relógios e mostradores diversos. Destas máquinas dependia o luxo e a vida na parte superior de Metrópolis, e estas mesmas máquinas eram a fonte da interminável labuta dos operários escravizados. Em poucas palavras, o luxo, a opulência e o conforto possíveis na 
superfície dependiam de que, na parte inferior da Cidade e da Sociedade, bem longe da vista dos privilegiados, uma massa de trabalhadores se esgotasse em uma interminável rotina e sob o peso de um ambiente ao qual não chegava nem a luz do sol nem o ar puro.

O mundo socialmente dividido da Metrópolis conta ainda com as suas tecnologias de controle social e com os seus amortecedores políticos. O tenso potencial operário de revolta parece estar contido por um discurso de conciliação de classes, na verdade surgido espontaneamente na parte inferior da sociedade, e que tem entre seus principais difusores a heroína do filme - uma filha da classe operária chamada Maria e que promove nas Catacumbas reuniões regulares, nas quais busca divulgar as idéias pacifistas de que um dia viria até eles um "mediador" capaz de obter das elites uma vida mais digna e menos penosa para os operários. Esse salvador seria uma espécie de "coração mediador" que conseguiria um dia conciliar o "cérebro" (os industriais que regiam Metrópolis) com as "mãos que constroem" (os operários das profundezas). Através deste Messias se tornaria por fim possível a mediação entre o Céu e o Inferno, entre o mundo da superfície as profundezas da labuta operária.

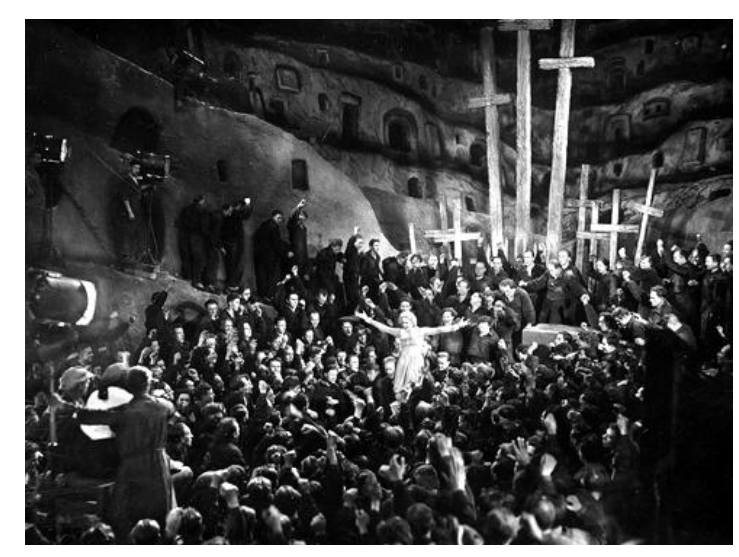

Figura 6. Maria e sua pregação para os operários - reunião nas Catacumbas. Metrópolis Imagem disponível em http://ning.it/fYNLRn

Maria, líder operária pacifista que apregoa a vinda de um messias ou "mediador" que um dia virá para salvar a humanidade trabalhadora com a conquista de uma conciliação social, parece prefigurar simultaneamente as figuras de João Batista - profeta do Novo Testamento 
que anuncia a vinda do Cristo - a de Maria, que lhe empresta o nome, e a de Madalena, trazendo o seu quinhão de sedução, que terá a sua importância no desenrolar da trama.

De fato, a trama de Metrópolis se complica precisamente quando Frede, filho de um dos mais poderosos industriais que controlam Metrópolis, apaixona-se por Maria e resolve segui-la e descer até as profundezas para ver como vivem as classes operárias. O filme, naturalmente, é repleto de simbologias, e a descida às profundezas sociais do proletariado, o mundo daqueles "que constroem”, é apenas mais uma delas. A descida de Frede em busca de Maria remete à descida aos Infernos, de Orfeu, mas também à metáfora da divisão bíblica entre Céu e Inferno, este último correspondendo ao penoso submundo de trabalho dos operários que mantém o funcionamento de Metrópolis. Em sua decida aos subterrâneos sociais, Frede acaba por assistir a uma traumatizante cena de acidente de trabalho na qual, após a explosão de uma máquina que deixa um saldo de diversos operários mortos, os trabalhadores são descartados como meros objetos e imediatamente substituídos ${ }^{13}$. Neste momento, Frede é acometido por uma espécie de visão delirante através da qual enxerga a "Máquina" como um monstro que devora impiedosamente os pobres trabalhadores. Depois disso, o jovem burguês da superfície chega a se disfarçar e a se infiltrar entre as fileiras de trabalho dos operários para sentir de maneira concreta a difícil vida dos operários. $\mathrm{O}$ contato com Maria e a revelação das difíceis condições de vida das massas operárias contribuem para operar nele uma transformação, e será ele quem desempenhará o papel do "mediador" cuja vinda fora dia fora profetizada pela líder operária pacifista, de certo modo ela mesma tornando-se a "mãe" do libertador que fizera nascer em Frede e também a heroína que o enlaçará amorosamente.

Outro complicador na trama de Metrópolis - e também uma de suas mais interessantes antevisões do futuro - é a invenção, por um cientista louco chamado Rotwang, de um surpreendente robô ${ }^{14}$. Rotwang esclarece ao mais poderoso dos industriais de

\footnotetext{
13 A explosão é provocada quando um operário sucumbe à exaustão, e na seqüencia diversos operários são atirados do alto como se fossem pedaços ou peças da própria máquina.

${ }^{14} \mathrm{O}$ mote do homem criado artificialmente já aparece no Cinema Alemão em uma série de seis filmes produzidos entre 1916 e 1917 por Otto Rippert (1869-1940), com o título Homunculus. Como o robô inventado na Metrópolis de Fritz Lang, evidencia-se desde aqui uma leitura negativa da possibilidade de criação de humanóides em laboratórios ou através da robótica. O robô de Metrópolis irá receber uma personalidade manipuladora e destrutiva; o homúnculo de Otto Rippert revolta-se contra a sua condição não-humana ao descobrir que havia sido criado em laboratório, e a partir daí passa a acalentar sonhos de dominar o mundo. Esta película foi analisada em maior detalhe em QUARESMA, L. "Homunculus: a Project for a modern cinema" in ELSAESSER, T. (org.), A Second Life: German Cinema's first decades. Amsterdã: Amsterdam University Press,
}

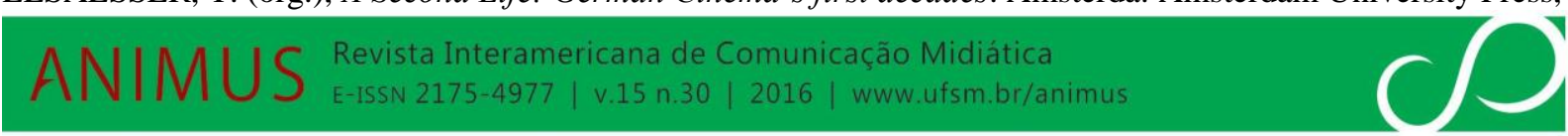


Metrópolis, Joh Fredersen - por acaso o pai de Frede - que em um futuro bem próximo o robô poderia, através de sua reprodução em série, favorecer a substituição imediata da massa trabalhadora na realização de suas tarefas diárias. Esta possibilidade faz com que o industrial conceba o plano de utilizar o robô para estimular entre os operários uma hostilidade contra as máquinas que eles mesmos manuseavam, na verdade já antevendo o desfecho de uma revolta com aquelas proporções, que seria a eclosão explosões na zona das máquinas e a conseqüente inundação da zona familiar operária, esta na qual residiam os filhos e famílias proletárias futura geração de operários que em breve estaria obsoleta com a disseminação de robôsoperários.

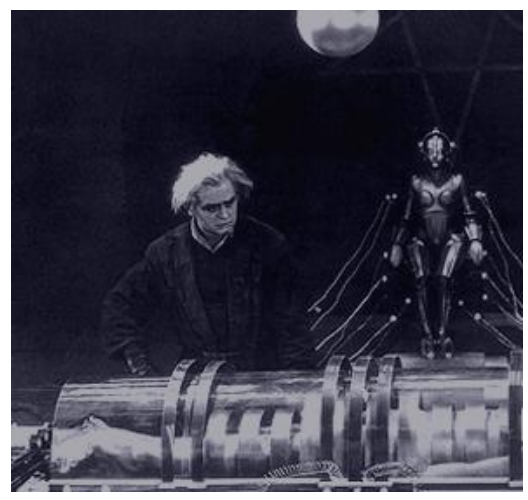

Figura 7. Construção do Robô pelo cientista-louco.

Imagem disponível em http://ning.it/fYNLRn

Essa passagem no roteiro de Lang é um pouco obscura com relação aos seus propósitos, e gera controvérsias. Podemos nos perguntar que vantagem poderia ser obtida, pelo mega-industrial Fredersen, ao se passar da política conciliatória a uma incitação de hostilidade contra o próprio sistema que ele comandava? Postula-se que, nesta nova situação, o industrial poderia utilizar o aparelho repressivo contra os operários, eliminando-os no conflito e, sobretudo, exterminando seus filhos, e que desta maneira estaria assegurada uma passagem para um novo mundo no qual o trabalho seria feito por máquinas sem que precisasse arcar com o ônus de ter deixado os operários desempregados para morrerem de fome.

1996. Nela, o autor identifica alguns elementos que seriam bem explorados pelo Cinema expressionista Alemão, na década de 1920. 
Para o encaminhamento do plano do Industrial, pede-se ao cientista louco que transforme o robô recém-inventado em um clone da líder religiosa Maria - ela mesma imediatamente aprisionada e tirada de cena - de modo a que o robô pudesse se infiltrar entre os trabalhadores e substituir o discurso de conciliação das máquinas pelo de 'ódio à maquinaria'. Compelidos à Revolta, os operários investem freneticamente em um movimento de destruição das máquinas que termina por explodir reservatórios que terminarão por colocar em risco as suas próprias vidas e as suas famílias. Ao perceberem seu erro, os operários resolvem condenar Maria - na verdade o andróide que se faz passar por Maria - à fogueira, e depois que as chamas consomem o revestimento do andróide percebem que, na verdade, tratava-se de um robô que se fizera passar por Maria. Esta retorna, depois de ter conseguido fugir do aprisionamento, e juntamente com Frede consegue salvar os filhos dos operários da inundação da cidade.

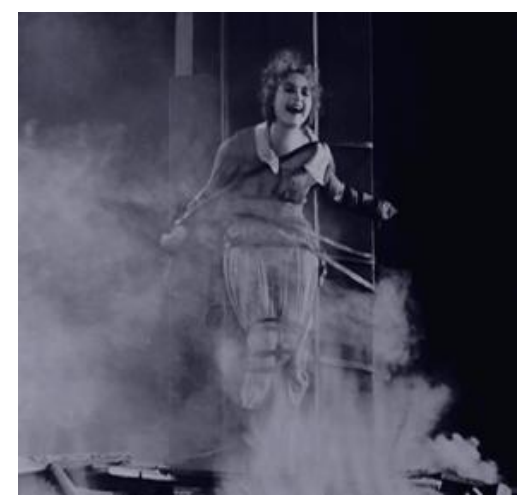

Figura 8. Cena da Inquisição. Revelando a clonagem de Maria Imagem disponível em http://ning.it/fYNLRn

Ao fim destes conturbados acontecimentos, os trabalhadores, liderados por um dos seus líderes, terminam por se reunir com o industrial que controla Metrópolis, sob a mediação de seu filho Frede - o tão prometido "coração mediador" - que termina por conseguir realizar a propalada conciliação de classes a partir do planejamento da minimização da desigualdade social e da concretização de melhores condições de vida para os operários. O final apresentado por Lang até hoje gera polêmicas interpretativas. Representaria uma vitória da classe trabalhadora, que finalmente consegue, na cena final, impor a sua participação no poder e derrotar a estrutura totalitarista? Neste caso, a cidade futurista também poderia ser tomada como metáfora para a Fábrica ou para o mundo do trabalho, e a celebração do acordo poderia 
ser interpretada como símbolo da conquista operária de uma participação na gestão da empresa? Ou o final conciliatório que reúne o Céu e o Inferno de Metrópolis em um acordo celebrado a duas partes, e mediado por um salvador saído do próprio seio da classe dominante, poderia representar a manipulação ideológica da classe trabalhadora, desarticulando seu potencial de revolta em mais uma das cenas de efeito do grande drama da conciliação de classes? Esperança ou denúncia - que dimensões se acobertam sob o final proposto por Fritz Lang para a distopia por ele construída em Metrópolis?

De todo modo, considerando-se uma ou outra destas várias interpretações, o ambiente dramático que se afirma no decorrer da obra de Fritz Lang é mesmo o do pessimismo expressionista, ainda que seu desfecho acene com a possibilidade de uma interpretação otimista. Por outro lado, a mensagem subjacente é o do triunfo do sentimento sobre o mundo mecânico: o próprio Frede, ao apaixonar-se por uma filha da classe operária, transgride a mecânica social que rege este universo totalitário e socialmente bipartido. Ao lado disto, deve-se ter em conta que Lang encaminha em Metrópolis não uma crítica direta à Máquina e à sociedade mecanizada, mas sim uma crítica à utilização da máquina sem sentimento, isto é, a máquina utilizada não como meio para alcançar e assegurar o progresso, mas sim como recurso para escravizar o homem. Trata-se, sobretudo, de uma crítica à mecanização do homem, e não de uma crítica à máquina em si mesma ${ }^{15}$. Metrópolis não rejeita propriamente a máquina, e é digno de nota o fato de que grandes catástrofes ocorrem no filme a partir da destruição irracional das máquinas pelos operários que tinham sido manipulados pelo robô-agitador.

Perpassa a película, da igual maneira, o anseio por uma sociedade justa, no interior da qual sejam minimizadas as desigualdades sociais geradas pelo Capitalismo. Por outro lado, há que considerar que Tea Von Harbou, esposa de Fritz Lang, estava engajada no partido nacional-socialista. Embora Lang não se interessasse por política no sentido convencional, o papel desempenhado pela figura do trabalhador em sua trama não está propriamente em discordância em relação à busca de apoio das camadas trabalhadoras pelo discurso hitlerista naquele período em que procurava ascender ao poder. Também Hitler procurou empreender, na primeira fase de sua ascensão política, uma crítica ao capitalismo. Para além disto, a figura

${ }^{15}$ Referindo-se à Metrópolis de Fritz Lang, Lotte Eisner (1896-1983) faz notar, em certa passagem de A Tela Demoníaca, que "os habitantes da cidade subterrânea são autômatos, muito mais que o robô criado pelo inventor Rothwang. Suas pessoas se coadunam inteiramente com o ritmo das máquinas complicadas" (EISNER, L.H. $A$ Tela Demoníaca: as influências de Max Reinhardt e do expressionismo. Rio de Janeiro: Paz e Terra Instituto Goethe, 1985) [original: 1973].

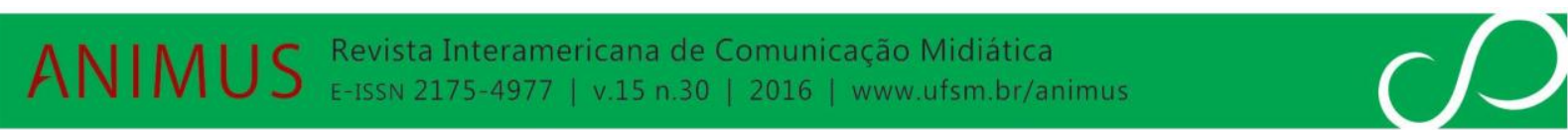


do líder saído do seio das classes dominantes e que desempenha a função de "coração mediador", o único capaz de conciliar o "cérebro que planeja" e as "mãos que constroem", não se opõe ao discurso hitlerista sobre a mediação que o partido nazista deveria encaminhar entre o mundo do trabalho e o capital ${ }^{16}$. Desta maneira, Metrópolis comporta, já à sua época, duas leituras: a da crítica social expressionista, e uma outra leitura, possível de se sintonizar com o nazismo em ascensão.

O filme não deixou de produzir novas leituras em momentos posteriores, e de estender suas influências a toda uma diversificada produção fílmica ainda por vir. Algumas cidades-cinema acompanham Metrópolis nos seus arroubos imaginativos; outras ficam um pouco aquém daquela ousadia imaginativa que até hoje impressiona aos que entram em contato com a obra de Lang pela primeira vez. Em um momento mais imediato, dois anos depois de Metrópolis, foi produzido por exemplo outro filme que apresenta uma cidadecinema projetada para o futuro: a Londres redesenhada por High Treason (1928), um filme inglês dirigido por Maurice Elvey (1887-1967) e que contou em seu elenco com a atuação de Raymond Massey (1896-1983) ${ }^{17}$. De todo modo, o futuro a que se refere High Treason é bem mais imediato, apontando mais precisamente para 1950, e de resto exercendo uma antevisão sobre um ambiente de nova Guerra Mundial prestes a aflorar. Hoje, a Londres Futura apresentada em High Treason impressionaria pouco, em comparação com as metrópoles contemporâneas, o que não é certamente o caso da Metrópolis de Fritz Lang, uma cidade futurista sempre impactante, mesmo nos dias de hoje.

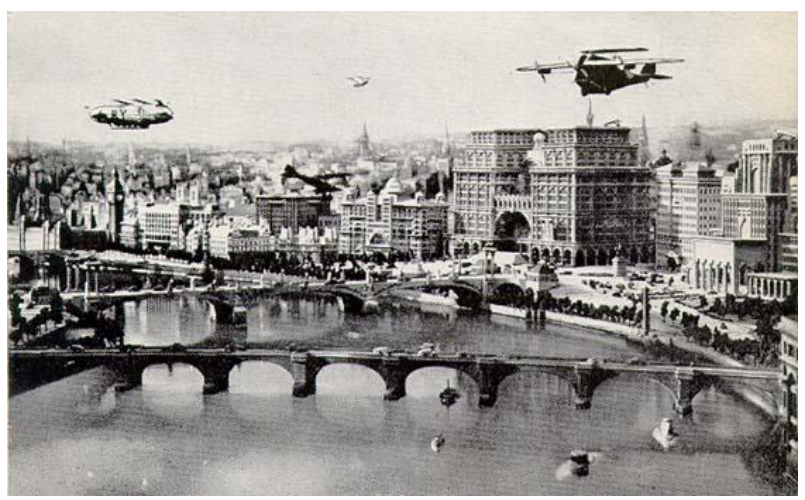

\footnotetext{
${ }^{16}$ Sobre as possibilidades de uma leitura de Metrópolis em sintonia com idéias nazistas, ver o ensaio "O Caso Fritz Lang” de Luís Nazário (As Sombras Móveis. Belo Horizonte: Editora UFMG, 2007).

${ }^{17}$ Além de Raymond Massey, o elenco de High Treason contou com James Carew, Humberstone Wright, Betina Hume e Jameson Thomas. O roteiro foi escrito por Noel Pemberton-Billing, e o filme, em preto e branco e com duração de 1 hora e 33 minutos, foi produzido pela_Gaumont British Picture Corporation.
}

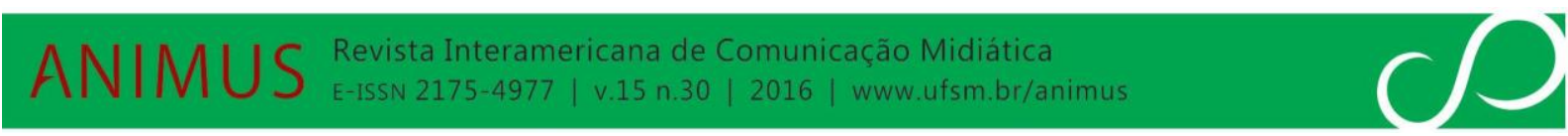


Figura 9. Londres futurista de High Treason (1928).

Disponível em http://ning.it/hUyNZV

De todo modo, a herança imaginária deixada por Metrópolis, de Fritz Lang, iria se estender promissoramente para o futuro. Novas possibilidades, inspiradas em elementos trazidos pela primeira vez com esta obra-prima do Cinema Expressionista Alemão, estariam por vir. Entre temores e fascínios, as demandas imaginárias relacionadas às diversas expectativas diante da progressiva urbanização do mundo moderno atravessariam o século. À extensão em altura seria logo acrescentada a extensão horizontal, referência ao ambiente urbano de megalópoles e conurbações que é tão típico da modernidade ${ }^{18}$. No limite, os cineastas das últimas décadas do milênio iriam nos oferecer cidades-cinema cujo crescimento horizontal mostra-se tão extenso que uma delas terminaria por recobrir o próprio planeta: a "Coruscant” da saga de Guerra nas Estrelas (1977 - 2005). Em contraste, esta mesma série de George Lucas nos oferece a cidade que atingiu as alturas celestiais, de modo a fugir do gás não respirável: a singular “Cidade das Nuvens” (Episódio II, 1980).

Eis aqui extensões das instigantes 'polêmicas da modernidade' que haviam fundado a Metrópolis de Fritz Lang. Destarte, a estas questões tão singularmente modernas - o crescimento vertical e horizontal da área urbana, a miséria de boa parte de uma população sempre crescente, o desemprego que ronda a classe trabalhadora e que funda a marginalidade a o crime, a solidão na multidão que se aperta em um tráfego sempre confuso e estressante de veículos vários - juntar-se-iam outras questões, já pós-modernas. Enquanto que o mundo de arranha-céus de Coruscant oferece-se como carne para problemas tipicamente modernos, o seu submundo - habitado e transitado por alienígenas de várias aparências e identidades planetárias - é já, de alguma maneira, caracteristicamente pós-moderno e bem fundado no mundo da crise de identidades que dará a tônica aos novos tempos. Mas esta já é outra questão a ser discutida.

\footnotetext{
${ }^{18}$ A Conurbação é um fenômeno tipicamente contemporâneo no qual ocorre a unificação da malha urbana de duas ou mais cidades, em conseqüência de seu crescimento geográfico.
}

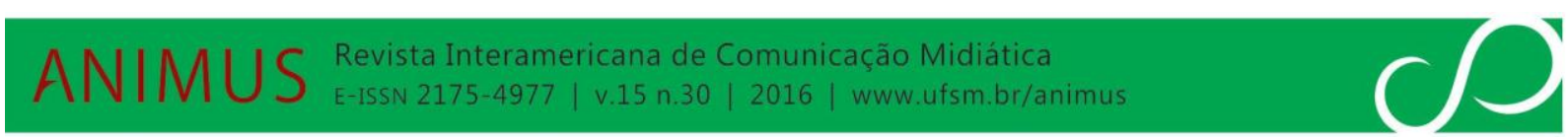



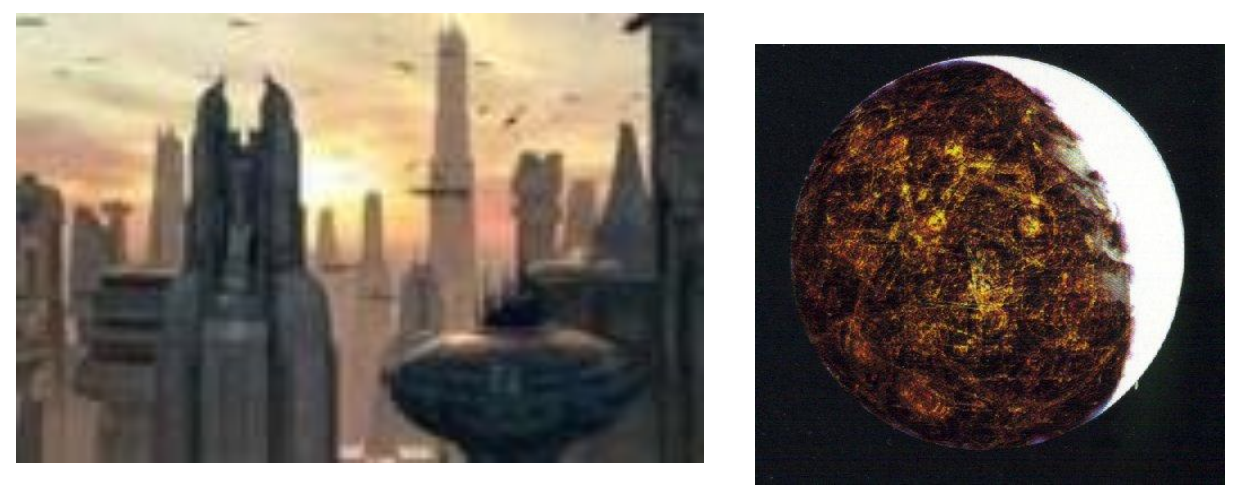

Figuras 10 e 11. Coruscant, a 'cidade-planeta'. (Guerra nas Estrelas, III, 2005) Disponíveis em http://ning.it/fpWvZ2 ${ }^{19}$ e http://ning.it/eNV32B

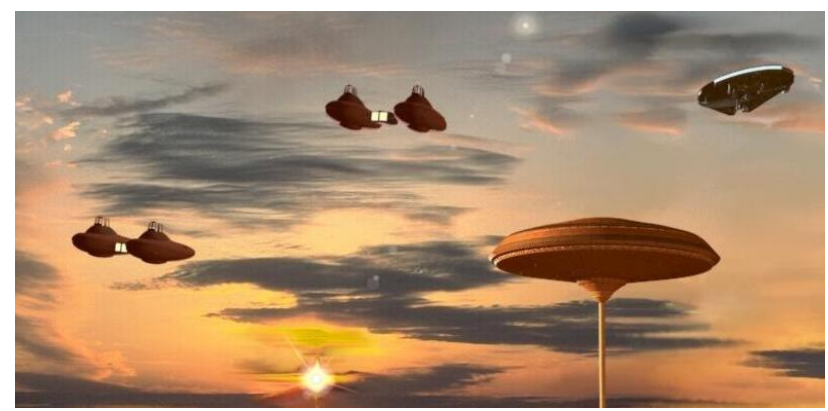

Figura 12. Cidade das Nuvens. (Guerra nas Estrelas, V, 1980) Disponível em http://ning.it/fVirNW ${ }^{20}$.

${ }^{19}$ Capital do Império na primeira trilogia de Guerra nas Estrelas, Coruscant é um autêntico 'planetacidade' ou 'cidade-planeta', conforme o ponto de vista, sendo totalmente coberto por gigantescos arranhacéus (a cidade se estende horizontalmente por todo o planeta, e apresenta alguns quilômetros de altura). Tal como a Metrópolis, de Lang, a megalópole-planeta apresenta também uma parte baixa da cidade, na qual a luz solar jamais chega e que constitui um submundo freqüentado por marginais e jogadores pertencentes a todas as espécies de alienígenas. De modo geral os moradores da parte inferior de Coruscant são mais pobres e não participam da sociedade mais rica que vive acima, nos edifícios. Deste modo, a divisão radical entre a boa sociedade e a cidade marginal (no caso de Metrópolis a 'cidade trabalhadora') faz-se também por uma oposição entre o alto e o baixo urbano. Vale lembrar ainda que o espaço aéreo intra-urbano de Coruscant é atravessado por incontáveis linhas de tráfego / O episódio da Saga que traz a cidade-planeta de Coruscant a primeiro plano é o Episódio III - Star Wars: Revenge of the Sith (2005). A cena inicial do episódio (battle over Coruscant) pode ser encontrada em: http://ning.it/f2hyyM

${ }^{20}$ A "Cidade das Nuvens" concretiza a solução ecológica encontrada no planeta Bespin, atravessado por várias camadas gasosas, sendo que apenas uma delas é respirável pela vida orgânica. A imagem, certamente, reflete os receios contemporâneos diante de um mundo superpoluído que precisará ser enfrentado em um futuro não tão distante. O trailer de Star Wars (Episode IV), na verdade o primeiro a ser filmado e ponto de partida da série (embora seja o quarto episódio da Saga Star Wars) pode ser encontrado em http://br.youtube.com/watch?v=9gvqpFbRKtQ. O episódio V é o que traz à cena Cloud City (1980). Uma fala de George Lucas sobre os efeitos especiais relacionados à Cloud City, pode ser encontrada em http://ning.it/fqGgo9. Imagens e explicações sobre Clouds City podem ser encontradas em http://ning.it/gZomuO

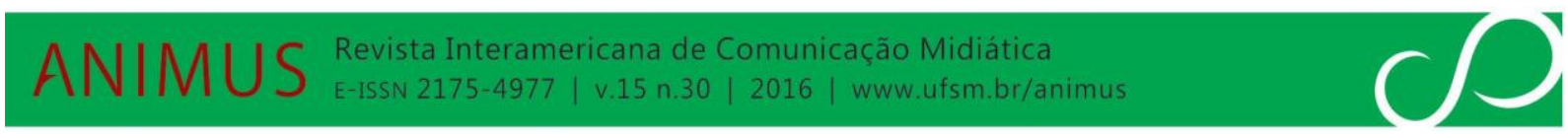




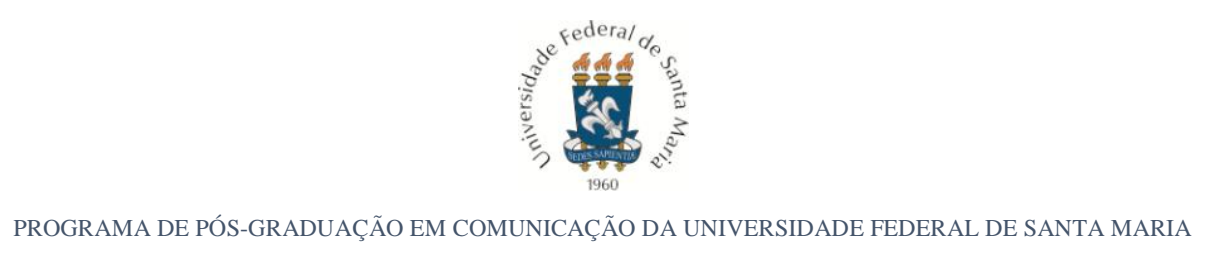

\section{REFERÊNCIAS BIBLIOGRÁFICAS E FILMOGRÁFICAS}

\section{Fontes Fílmicas}

Guerra nas Estrelas [Star Wars - Episódio IV: A New Hope] (EUA, 1977). Filme a cores, 121 minutos de duração. Ficha Técnica - Produtora e Distribuidora: 20th Century Fox Film Corporation; Direção: George Lucas. Roteiro: George Lucas. Produção: Gary Kurtz. Fotografia: Gilbert Taylor. Música: John Williams. Elenco: Harrison Ford (Han Solo), Carrie Fisher (Princesa Léia Organa), Mark Hamill (Luca Skywalker), Alec Guinness (Obi-Wan Kenobi), Peter Cushing (Grand Moff Wilhuff Tarkin), Peter Mayhew (Chewbacca), e grande elenco.

Guerra nas Estrelas [Star Wars - Episódio V: The Empire Strikes Back] (EUA, 1980). Filme a cores, 124 minutos de duração. Ficha Técnica - Produtora: Lucasfilms; Distribuidora: 20th Century Fox Film Corporation; Direção: George Lucas. Roteiro: George Lucas. Produção: Gary Kurtz. Fotografia: Peter Suschitzky. Música: John Williams. Elenco: Harrison Ford (Han Solo), Mark Hamill (Luca Skywalker), Carrie Fisher (Princesa Leia Organa), Alec Guinness (Obi-Wan Kenobi), Billy Dee Williams (Lando Calrissian), e grande elenco.

Guerra nas Estrelas [Star Wars - Episódio VI: Returno of the Jedi] (EUA, 1983). Filme a cores, 131 minutos de duração. Ficha Técnica - Produtora: Lucasfilms; Distribuidora: 20th Century Fox Film Corporation; Direção: Richard Marquand. Roteiro: George Lucas e Lawrence Kasdan, baseado em argumento de George Lucas. Produção: Howard G. Kazanjian. Fotografia: Alan Hume. Música: John Williams. Elenco: Mark Hamil (Lucas Skywalker); Harrison Ford (Han Solo); Carrie Fischer (princesa Leia Organa), Alec Guiness (Obi-Wan Kenobi), Peter Mayhew (Chewbacca), Sebastian Shaw (Anakin Skywalker), Frank Oz (Yoda), David Prowse (Darth Vader), Anthony Daniels (C3PO), e grande elenco.

Guerra nas Estrelas [Star Wars - Episódio I: A Ameaça Fantasma] (EUA, 1999). Filme a cores, 131 minutos de duração. Ficha Técnica - Produtora: Lucasfilms; Distribuidora: 20th Century Fox Film Corporation; Direção: George Lucas. Roteiro: George Lucas. Produção: Rick McCallum. Fotografia: David Tattersall. Música: John Williams. Elenco: Ewan McGregor (Obi-Wan Kenobi), Liam Neeson (Qui-Gon Jinn), Natalie Portman (Rainha Amídala), Jake Lloyd (Anakin Skywalker), Terence Stamp (Chanceler Finis Valorum), Samuel L. Jackson (Mace Windu), Ian McDiarmid (Imperador Palpatine / Darth Sidious), e grande elenco.

Guerra nas Estrelas [Star Wars - Episódio II: O Ataque dos Clones] (EUA, 2002). Filme a cores, 144 minutos de duração. Ficha Técnica - Produtora: Lucasfilms / Jak Productions; Distribuidora: 20th Century Fox Film Corporation; Direção: George Lucas. Roteiro: Jonathan Halles e George Lucas. Produção: Rick McCallum.

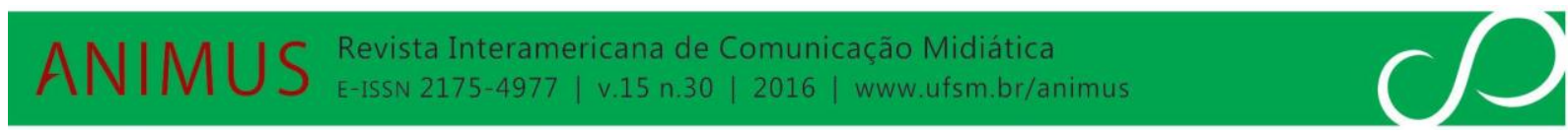


Fotografia: David Tattersall. Música: John Williams. Elenco: Ewan McGregor (ObiWan Kenobi), Hayden Christensen (Anakin Skywalker), Natalie Portman (Senadora Padmé Amídala), Christopher Lee (Conde Dooku / Darth Tyranus), Samuel L. Jackson (Mace Windu), Ian McDiarmid (Chanceler Palpatine / Darth Sidious), e grande elenco.

Guerra nas Estrelas [Star Wars - Episódio III: Revenge of the Sith] (EUA, 2005). Filme a cores, 146 minutos de duração. Ficha Técnica - Produtora: Lucasfilms; Distribuidora: 20th Century Fox Film Corporation; Direção: George Lucas. Roteiro: George Lucas. Produção: Rick McCallum. Fotografia: David Tattersall. Música: John Williams. Elenco: Ewan McGregor (Obi-Wan Kenobi), Hayden Christensen (Anakin Skywalker / Dart Vader), Natalie Portman (Senadora Amídala / Padmé Naberrie -Skywalker), Christopher Lee (Conde Dooku / Darth Tyranus), Samuel L. Jackson (Mace Windu), Ian McDiarmid (Chanceler Supremo / Imperador Palpatine / Darth Sidious), e grande elenco.

Guerra nas Estrelas (Star Wars). Trailer do filme. http://ning.it/gLsFY2

Guerra nas Estrelas (Star Wars - battle over Coruscant. Episode III). Cena Inicial. http://ning.it/f2hyyM

Guerra nas Estrelas (Cidade das Nuvens - vídeo com cenas do filme e explicações sobre a "Cidade das Nuvens"). http://ning.it/gZomuO

High Treason (Londres, 1928). Filme preto e branco, 93 minutos de duração. Ficha Técnica - Produtora e Distribuidora: Gaumont British Picture Corporation. Direção: Maurice Elvey. Roteiro: Noel Pemberton-Billing. Elenco: James Carew (Lord Rawleigh), Raymond Massey (Cabinet Member), Humberstone Wright (Dr. Seymour), Betina Hume (Evelyn Seymour), Jameson Thomas (Michael Deane) e grande elenco.

Homunculus (Alemanha, 1912). Filme preto e branco. Ficha Técnica - Produtora e Distribuidora: Deutsche Bioscop. Direção: Otto Rippert. Roteiro: Otto Rippert. Produção: Hanns Lippmann. Fotografia: Carl Hoffmann. Elenco: Olaf Fonss (Homúnculo). Friedrich Kühne (Edgar Rodin), Theodor Loos (Sven Friedland), Machtild Thein (Margot) e grande elenco.

A Ilha do Doutor Moreau. (EUA: 1933). Filme preto e branco, falado, 71 minutos de duração. Ficha Técnica - Produtora: Paramount Pictures; Direção: Erle C. Kenton; Roteiro: H. G. Wells, Waldemar Ypoung, Philip Wilie; Elenco: Charles Laughton, Richard Arlen, Leila Hyams, Bela Lugosi, Kathleen Burke e grande elenco.

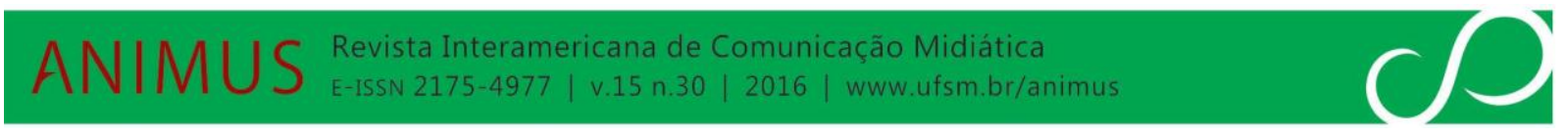


Matrix (EUA: 1999). Filme a cores, falado, 129 min. de duração. Distribuidora: Warner Bros. Direção: Andy Wachowski e Larry Wachowski. Roteiro: Andy Wachowski e Larry Wachowski. Produção: Grant Hill e Joel Silver. Fotografia: Bill Pope. Música: Don Davis. Elenco: Keanu Reeves (Neo / Thomas A. Anderson); Laurence Fishburne (Morpheus); Carrie Anne-Moss (Trinity); Huho Weaving (Agente Smith) e grande elenco.

Metropolis. (Alemanha: 1926). Filme preto e branco, mudo, 140 minutos de duração. Ficha Técnica - Produtora: Universum Film A. G.; Direção: Fritz Lang; Roteiro: Fritz Lang e Thea Von Harbou; Fotografia: Karl Freund e Gunther Rittau; Produção: Erich Pommer; Música: Gottfried Huppertz; Efeitos Especiais: Eugene Schufftan; Elenco: Brigitte Helm (Maria), Alfred Abel (John Fredersen), Gustav Frohlich (Freder), Rudolph Klein-Rogge (Rotwang), Heinrich George, Fritz Rasp.

Metrópolis. Trailer do Filme. http://ning.it/fUJIKm ... er_100.asf

Nosferatu. Filme completo. http://ning.it/f74PvO

Perfume - a história de um assassino. (França / Espanha / Alemanha: 2006). Filme a cores, falado, 147 minutos de duração. Ficha Técnica - Produtora: VIP 4 Medienfonds / Davis-Films / Ikirus Films S.L. / Constantin Film Produktion GmbH / Nouvelle Éditions de Films / Castelao Producciones S.A; Direção: Tom Tykwer; Roteiro e idealização: Andrew Birkin, Tom Tykwer e Bernd Eichinger, baseado em livro de Patrick Süskind; Produção: Nernd Eichinger; Fotografia: Frank Griebe; Música: Reinhold Heil, Johnny Klimek e Tom Tykwer; Elenco: Ben Whishaw (Jean-Baptiste Grenouille), Alvaro Roque (Jean-Baptiste Grenouille - 5 anos, Franck Lefeuvre (JeanBaptiste Grenouille - 12 anos), Dustin Hoffman (Giuseppe Baldini); Alan Rickman (Antoine Richis), e grande elenco.

O Quinto Elemento. (França: 1997). Filme a cores, falado, 127 minutos de duração. Ficha Técnica - Produtora: Columbia Pictures / Gaumont / Sony Pictures Entertainment; Direção: Luc Besson; Roteiro e idealização: Luc Besson, baseado em estória de Luc Besson e Robert Mark Kamen; Produção: Patrice Ledoux; Fotografia: Thierry Arbogast; Música: Eric Serra; Elenco: Bruce Willis (Korben Dallas), Milla Javivich (Leeloo), Gary Olsman (Jean-Baptiste Emmanuel Zorg), Ian Holm (Padre Vito Cornelius); Chris Tucjer (Ruby Rhod), e grande elenco.

Tempos Modernos (Charles Chaplin, 1936). Cena do filme: operário enlouquecido. http://ning.it/eAPQok

1984. (Inglaterra: 1984). Filme a cores, falado, 115 minutos de duração.

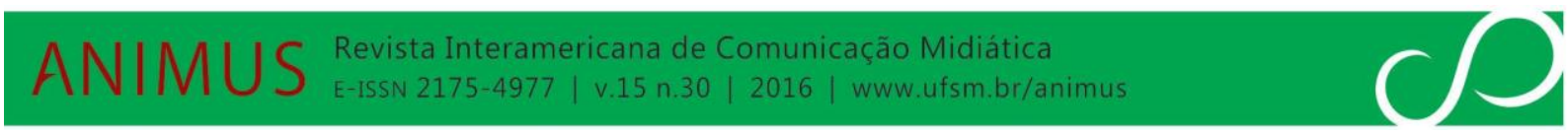


Ficha Técnica - Produtora: Umbrella-Rosenblum / Virgin Productions; Direção: Michael Bradford; Roteiro e idealização: Michael Radford; Fotografia: Roger Deakins; Produção: Simon Perry; Música: Eurythmics e Dominic Muldowney; Elenco: John Hurt (Winston Smith), Richard Burton (O’Brien), Suzanna Hamilton (Julia), Bob Flag (Big Brother), e grande elenco.

1984. Trailer do filme. http://ning.it/gU2vlD

\section{FONTES LITERÁRIAS}

BACON, Francis. "A Nova Atlântida" in Os Pensadores. São Paulo: Abril Cultural, 1980, volume 13 [publicação original, póstuma:1627].

CAMPANELLA, Tomaso. "Cidade do Sol” in Os Pensadores. São Paulo: Abril Cultural, 1980, volume 12 [original: 1602]

CLARKE, Arthur. 2001: Uma Odisséia no Espaço. New York: Paperback, 2000. [escrito entre 1964 e 1968; publicação original: 1968]

HUXLEY, Aldous. Admirável Mundo Novo. São Paulo: Abril Cultural, 1974 [original: 1931].

MORUS, Thomas. "Utopia" in Os Pensadores. São Paulo: Abril Cultural, 1980, volume 12 [original: 1516]

ORWELL, George. 1984. Lisboa: Antígona, 2004 [original: 1948] [Publicação original: London: Secker \& Walburg, 1949]

PLATÃO, A República, Lisboa: Fundação Calouste Gulbenkian, 1993.

WELLS, H. G. A Ilha do Doutor Moreau. Lisboa: Europa-América, 1989 [original: 1896].

\section{BIBLIOGRAFIA CITADA}

CÁNEPA, Laura Loguércio. "Expressionismo Alemão" in MASCARELLO, Fernando (org.). História do Cinema Mundial. São Paulo: Papirus, 2006.

CARDINAL, R. O Expressionismo. Rio de Janeiro: Jorge Zahar, 1988.

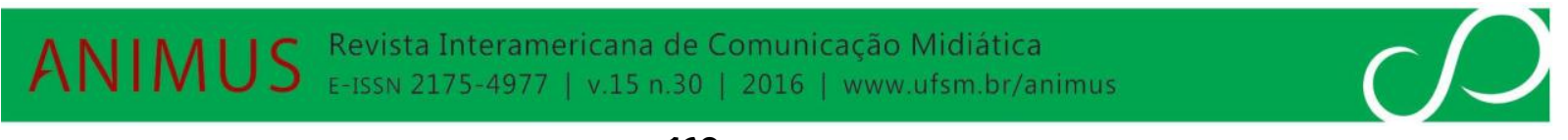


EISNER, L.H. A Tela Demoníaca: as influências de Max Reinhardt e do expressionismo. Rio de Janeiro: Paz e Terra Instituto Goethe, 1985 [original: 1973].

ELSAESSER, T. (org). Weimar cinema and after: Germany's historical imaginary. Londres: Routledge, 2000.

FERRO, Marc. Cinema e História. São Paulo: Paz e Terra, 1992 [original francês: 1976].

GAY, Peter, A cultura de Weimar. Rio de Janeiro: Paz e Terra, 1978 [original: 1968].

GRIERSON, John. "Primeiros Princípios do Documentário" in Revista Cinemais, n.8, p.65-66, nov./dez. de 1997. Campinas [original: 1932-1934].

HARDLY, Forsyth. Grierson on documentary, Los Angeles: University of Califórnia Press, 1966.

HILLEGAS, Mark R. The Future as Nightmare: H.G. Wells and the Anti-Utopians. Illinois: Southern Illinois University Press, 1967.

JACOBY, Russell. Imagem Imperfeita: Pensamento Utópico para uma Época Antiutópica. Rio de Janeiro: Civilização Brasileira, 2007 [original americano: 2005].

JONES, L. E. "Culture and politics in the Weimar Republic" in MARTEL, G (org) Modern Germany reconsidered (1870-1945), Londres: Routledge, 1992.

KRACAUER, S., De Caligari a Hitler: uma história psicológica do Cinema Alemão, Rio de Janeiro: Jorge Zahar, 1988 [original em inglês: 1947].

KUMAR, Krishan, Utopia and Anti-Utopia in Modern Times, Cambridge Ma: Oxford UK, 1987.

MORIN, Edgar. O Cinema ou o Homem Imaginário. Lisboa: Relógio D’Água, 1997 [original francês: 1956].

NAZÁRIO, Luiz. “O Caso Fritz Lang” in As Sombras Móveis. Belo Horizonte: Editora UFMG, 2007.

QUARESMA, L. "Homunculus: a Project for a modern cinema" in ELSAESSER, T. (org.), A Second Life: German Cinema's first decades. Amsterdam: Amsterdam University Press, 1996.

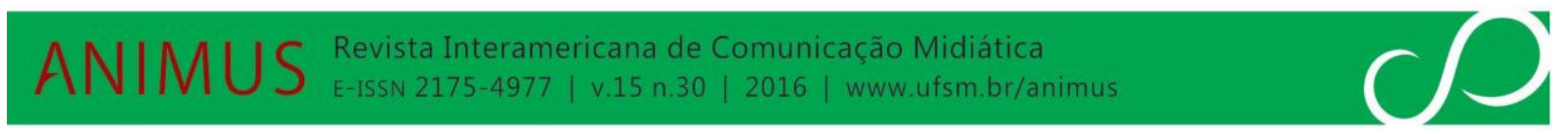


Professor adjunto da Universidade Federal Rural do Rio de Janeiro (UFRRJ), nos cursos de graduação e pós-graduação em História, e professor colaborador no Programa de Pós-Graduação em História Comparada da UFRJ. Doutor em História pela Universidade Federal Fluminense

Esta obra está licenciada sob uma Licença Creative Commons. 